\title{
A sala de aula crítica: um novo olhar para o livro didático em cursos de línguas adicionais
}

\author{
Ana Lígia Barbosa de Carvalho e Silva \\ Universidade Estadual de Campinas - Unicamp \\ Luciana Amgarten Quitzau \\ Universidade Estadual de Campinas - Unicamp
}

\begin{abstract}
Resumo
O objetivo deste estudo é propor uma análise crítica de uma atividade pedagógica sugerida em um livro didático de inglês, amplamente utilizado em salas de aula de inúmeros institutos particulares de idiomas no Brasil. Tal análise busca redirecionar o olhar de professores e alunos quanto ao uso do livro didático, muitas vezes (im)posto como principal, ou única, fonte de recursos pedagógicos. Para guiar nossa análise, propomos a seguinte pergunta: em que medida o conteúdo abordado pelo livro didático é implicitamente permeado por ideologias que se distanciam do contexto da aprendizagem? Baseadas na perspectiva da "Pedagogia Crítica Revolucionária", proposta por Scheyerl (2012), que sugere a produção de "material de dentro", buscamos identificar como o professor poderá não ser silenciado, adaptando sua prática e suas convicções ao livro didático, na perspectiva de uma sala de aula crítica.
\end{abstract}

Palavras-chave: Material didático. Sala de aula crítica. Ensino de língua adicional.

\begin{abstract}
The aim of this study is to propose a critical analysis of a pedagogical activity suggested in an English textbook that is widely used in classrooms, in a number of private language institutes in Brazil. This analysis seeks to redirect the view of teachers and students in the use of textbooks often imposed as the main, or only teaching resource. To guide our analysis, we pose the following question: to what extent is the content covered by the textbook implicitly permeated by ideologies that are distant from the learning context? Based on Scheyerl's (2012) "Revolutionary Critical Pedagogy", which suggests the production of "inside material", we attempt to identify how the teacher cannot be silenced, adapting his or her practice and convictions to the textbook, in the perspective of a critical classroom.
\end{abstract}

Keywords: Textbooks. Critical classroom. Teaching of aditional languages.

\section{A ESCOLHA DE UM MATERIAL DIDÁTICO}

Tanto no contexto de escolas públicas e particulares como em institutos particulares de idiomas, a escolha de um livro didático (LD) parece constituir um dilema constante para os professores. Por questões circunstanciais, alguns professores aderem ao uso de um livro 
muitas vezes como instrumento norteador do próprio currículo, sem a devida reflexão. Tal fato parece ocorrer por duas razões principais, como veremos a seguir.

Por um lado, como aponta Harwood (2010, p. 4), vários fatores dificultam a produção de material autêntico pelos próprios professores, como escassez de tempo, carga horária de ensino sobrecarregada e até mesmo restrições quanto a práticas que desviem de um currículo rígido já estabelecido. Por outro, a escolha de um LD produzido por grandes editoras tampouco parece constituir solução para as complexas e distintas necessidades existentes no processo de ensino/aprendizagem de uma língua adicional.

Neste sentido, Allwright (1981, apud Harwood, 2010) afirma que nenhum material pré-preparado poderá atender, com precisão, às diversas necessidades existentes nas salas de aulas. O autor enfatiza que certo nível de adaptação sempre se faz necessário para que o LD possa ser apenas um ponto de partida, um recurso a mais, na elaboração de um curso. $\mathrm{Na}$ mesma direção, Dudley-Evans e St. John (1998, p. 173) sugerem que os professores sejam capazes de selecionar, fazer uso criativo, modificar e suplementar o material disponível, a fim de adequá-lo às necessidades dos aprendizes.

No entanto, Rojo (2013, p. 170 - 172), alerta que pode haver problemas nas três alternativas que parecem restar aos professores na escolha de um material didático: 1) tornarse refém do livro escolhido; 2) ter ampla autonomia, porém não ser capaz de viabilizar sua própria produção de material por razões práticas de tempo e meios; 3) selecionar vários livros com os quais se alinha e deles extrair seu melhor, porém correndo o risco de produzir uma mera "colagem de textos e atividades de LD com propostas muitas vezes disparatadas e contraditórias" (ROJO, 2013, p. 172).

Este estudo pretende contribuir para que professores e alunos assumam uma postura crítica em relação aos materiais didáticos utilizados em aulas de língua, fazendo uma análise crítica de uma atividade que faz parte de um livro didático de ensino de inglês bastante adotado no Brasil. Ele está organizado da seguinte forma: após esta seção, na qual introduzimos algumas reflexões pertinentes à escolha de um material didático, discorreremos sobre os fundamentos teóricos que sustentam a análise a que nos propomos, destacando alguns mitos que, segundo a concepção de Scheyerl (2012), são representados nas tarefas propostas, e discutindo o papel do LD na sala de aula. Logo depois, explicitaremos brevemente a abordagem metodológica escolhida - a análise qualitativa do conteúdo, conforme Harwood (2010) e Lankshear e Knobel (2008). Em seguida, faremos a apresentação e a análise da atividade selecionada para este estudo. Por fim, a partir de uma perspectiva 
crítica, faremos uma proposta alternativa de uso das atividades analisadas, tendo a reflexividade como fundamento para mudanças.

\section{FUNDAMENTOS TEÓRICOS PARA ANÁLISE DO MATERIAL}

\section{Ideologia}

Dentre os possíveis e variados enfoques para abordarmos a presença da ideologia em materiais didáticos, pautaremos nossos estudos nos ensinamentos de Rajagopalan (2012, p. 68), para quem a ideologia é um fenômeno cujo funcionamento se dá em larga medida, de modo inconsciente, silencioso e furtivo. Para esse mesmo autor, a ideologia permeia o ensino de línguas de modo sorrateiro e silencioso, já que ela

[...] ofusca nossa capacidade de discernimento e percepção do significado real das coisas, desviando nosso olhar para coisas que dizem respeito apenas à superfície das questões ou a questões relevantes a uma determinada visão do mundo. (RAJAGOPALAN, 2012, p. 68).

Tendo em vista a massiva procura por cursos de inglês, típica do contexto transcultural em que as sociedades estão imersas, o que se vê atualmente é que o ensino de inglês tem se transformado em uma commodity, ou um simples bem de consumo. Neste sentido, Silverman (1991, apud Harwood, 2010, p. 15) chega a comparar a produção de livros didáticos à de outros "produtos", como cereais matinais, automóveis ou sapatos, visando unicamente ao lucro. Mehlinger (1991, apud Harwood 2010, p. 15) ressalta, ainda, a excessiva importância que tem sido atribuída às qualidades visuais dos livros didáticos.

Selecionar um livro didático e decidir como utilizá-lo parece, portanto, constituir uma das fases mais cruciais na elaboração de um curso. $\mathrm{O}$ que parece estar em jogo são as relações conflitivas, marcadas por interesses diversos, entre os responsáveis pela elaboração, produção e venda dos livros didáticos em contraponto com os interesses genuínos daqueles que deles farão uso.

O grande dilema entre professores, usuários de livros didáticos para fins pedagógicos e consumidores de commodities traduz-se nas reflexões de Rocha e Maciel (2013, p. 13) sobre "[...] que tipo de conhecimento deveria ser valorizado na escola", ou ainda, "[...] 'o conhecimento de quem vale mais' e por que alguns saberes se sobrepõem a outros.”.

A tensão gerada pelo uso do livro didático em sala de aula pode ser vista sob dois aspectos. Por um lado, os livros didáticos são influenciados pela visão hegemônica de seus elaboradores, geralmente grandes editores provenientes de países do círculo central, que se 
consideram detentores naturais da língua. Nesse sentido, Matsuda (2012, p. 171) aponta que os materiais didáticos, em geral, tendem a reforçar a ideia de que o inglês é a língua do círculo central e que por essa razão deve ser aprendido para tornar possível a interação com falantes nativos, em especial dos Estados Unidos e do Reino Unido.

Por outro lado, os professores e alunos que fazem uso do material em institutos de idiomas estão sujeitos, além de suas próprias convicções, à ideologia da instituição a que estão vinculados. No entanto, Kramsch (1993) afirma que professores e alunos usam o sistema já estabilizado para promoverem seus próprios significados locais e pessoais, estando “[...] constantemente engajados na criação de uma cultura do terceiro tipo por meio do dar-ereceber do diálogo da sala de aula" (p. 23, tradução nossa ${ }^{1}$ ).

Para a mesma autora, cabe, sim, ao professor adaptar o material para uso em sala de aula, a fim de quebrar a tensão entre necessidades globais, ditadas de cima para baixo e impostas aos professores por meio de diretrizes de Estado e da "indústria do livro", e as necessidades locais dos estudantes que tentam se inserir na cultura do outro, por meio do aprendizado da língua estrangeira.

Cabe, portanto, sublinhar o papel fundamental que o professor de línguas deve exercer na escolha e na utilização do LD, como parte de suas práticas didáticas.

O professor, portanto, deveria pensar se o que está fazendo em sala está dando condições aos seus alunos de agirem no mundo real de maneira eficiente através da linguagem, de forma que possam exercer a cidadania, conscientes sobre o papel da linguagem na construção de identidades e no estabelecimento das relações de poder (SCARAMUCCI; RODRIGUES, 2005, p. 70).

Assim, o professor crítico passa a desempenhar a função de mediador no processo de construção de sentidos e de desestabilização de estereótipos que podem surgir durante a realização de tarefas propostas pelos LDs.

A presença de estereótipos em livros didáticos é ressaltada por Kawachi e Lima (2013, p. 97), para quem o ensino de língua estrangeira, para nós língua adicional, não ocorre de forma neutra, sem implicações ou consequências. Afirmam os autores que:

O problema da inclusão de apenas imagens culturais 'tradicionais' no ensinoaprendizagem de LE (especialmente em LDs) está na desconsideração de práticas culturais de grupos marginalizados em prol da apresentação somente de expressões culturais legitimadas, que favorecem os interesses exclusivamente de uma classe: a

\footnotetext{
1 ' [...] learners as well as teachers repeatedly use the system to promote their own local and personal meanings as well as for their cultures, they are constantly engaged in creating a culture of the third type through the giveand-take of classroom dialogue". (KRAMSCH, 1993, p.23)
} 
dominante. Nesse sentido, há uma simplificação e/ou generalização da realidade, o que acaba por distorcê-la, podendo gerar estereótipos (KAWACHI; LIMA, 2013, p. 97).

Diante desse complexo panorama, entendemos que cabe ao professor crítico, então, perguntar-se: como aproximar as tarefas propostas pelo LD ao contexto cultural em que a classe está inserida? Como os alunos serão capazes de relacionar as discussões em sala de aula às suas práticas fora dela? Como as reflexões sobre as tarefas propostas pelo livro didático serão úteis para levar o aluno a ser um cidadão crítico, autônomo e atuante no contexto social?

\section{Perspectiva crítica para a sala de aula}

Inicialmente, esclarecemos que não faz parte do escopo deste estudo nos aprofundarmos em intensas discussões teóricas relativas à criticidade. Para nossos propósitos, buscamos tão somente lançar novas perspectivas e olhares em relação a práticas de sala de aula, em especial em relação ao uso de livros didáticos como aspecto fundante na formação de professores e alunos reflexivos e engajados socialmente.

Nessa direção, ao discorrer sobre o letramento crítico, Monte Mór (2013, p. 31) salienta que a linguagem tem natureza política em função das relações de poder nela engendradas. A autora prossegue afirmando que "todo discurso - em acepção ampla, independente da modalidade e contexto em que se apresenta - é permeado por ideologias."

Benesch (2010, p.112-113), sob a visão da Linguística Aplicada Crítica, vê os professores críticos como facilitadores da relação poder/resistência, capazes de propor estratégias que desafiem o modo como as coisas estão.

Scheyerl (2012, p. 47), por sua vez, vai além e sustenta, por meio da "Pedagogia Crítica Revolucionária", que as salas de aula de língua estrangeira precisam "debater e contestar valores implantados pelas grandes editoras", que ela considera "porta-vozes contundentes e históricos" dos três mitos por ela enumerados. São eles: i) mito da mímese (ou do colonizador). O material didático gera no aprendiz a rejeição da própria identidade e a vontade de ser o outro, em geral pertencente ao mundo WASP, acrônico para as palavras em inglês White, Anglo Saxon Protestant; ii) mito do melting pot. As culturas estrangeiras são representadas nos livros didáticos como algo exótico, interessante ou alvo de admiração, constituindo uma falsa adoção do multiculturalismo; iii) mito do consumismo. O livro didático se presta a servir como meio de homogeneidade cultural, estimulando a venda de produtos e marcas e associando mercadorias a valores e crenças. 
A autora sugere a utilização do que chama de "materiais de dentro", ou seja, materiais autênticos capazes de problematizar questões culturais, substituindo a visão etnocêntrica, própria dos LDs de língua adicional. Scheyerl, (2012, p. 49) sugere que esse material de dentro seja "[...] incorporado à prática em sala de aula como um instrumento de mediação importante para o desenvolvimento da consciência crítica e para a aprendizagem da língua alvo."

\section{METODOLOGIA DE ANÁLISE}

A análise qualitativa do conteúdo, segundo Pingel (1999, apud Harwood, 2010), pode ser utilizada como um modo interpretativo de análise que visa a descobrir significados e valores transmitidos por materiais didáticos. O foco deste tipo de análise está tanto na língua ensinada como no conteúdo temático das tarefas, que revelam as visões de mundo dos autores dos materiais.

Para Lankshear e Knobel (2008, p. 274 - 275), a análise qualitativa de conteúdo tem por objeto "os tipos de mensagens que os textos enviam e com que normas e ideologias essas mensagens codificam". Os autores ressaltam que este tipo de análise é usado em textos, em sua mais ampla acepção: documentos, livros, letras de canções, filmes, propagandas, websites e diferentes formas de narrativas.

Para realizarmos a análise qualitativa do conteúdo a que este estudo se propõe apoiaremo-nos na visão de Lemke (2010, p. 456), segundo a qual imagem e texto compõem um todo indivisível na construção de significados. O autor define "letramento" como "um conjunto de competências culturais para construir significados sociais reconhecíveis através do uso de tecnologias materiais particulares". Para Lemke, "todo letramento é letramento midiático: você nunca pode construir significado com a língua de forma isolada." (LEMKE, 2010, p. 456)

O mesmo autor nos lembra que os significados das palavras e das imagens não ocorrem de forma somativa (o significado da palavra mais o da imagem), mas sim, de forma multiplicativa, pois "o significado da palavra se modifica através do contexto imagético e o significado da imagem se modifica pelo contexto textual." (LEMKE, 2010, p. 456), fazendo do todo algo muito maior que a soma das partes.

A análise do conteúdo linguístico, com foco na língua em si, volta-se para a observação da língua em uso e a compara com aquela representada nos LDs. Analisam-se, por 
exemplo, questões pragmáticas e de gênero, contrastando-se interações em diálogos do livrotexto com a língua efetivamente utilizada nas interações reais.

Para efeitos deste estudo, voltamos nossa atenção para a análise do conteúdo cultural, pois conforme Harwood (2010, p. 10-11), os materiais são vistos, além de meio para o ensino da língua, como "artefatos culturais de seus conteúdos temáticos".

Neste estudo, analisaremos como o conteúdo do material didático em questão transmite, além da língua, mensagens de cunho cultural, entendendo-se por "leitura" tudo aquilo que o aluno processa e absorve por meio de textos escritos e imagens.

Com base em todo o exposto, passaremos agora à apresentação e à análise do material didático.

\section{DESCRIÇÃO E PROBLEMATIZAÇÃO DO MATERIAL DIDÁTICO}

A atividade que analisaremos neste estudo é parte do livro American English File, Student Book, volume 1 (OXENDEN; LATHAM-KOENIG; SELIGSON, 2008). Trata-se de um material destinado ao ensino de inglês para jovens e adultos que integra o catálogo de livros para ensino de línguas da Oxford University Press, editora ligada à universidade de Oxford, que produz, dentre outras publicações, livros didáticos que são adotados em vários países do mundo. No catálogo online da editora, esse livro é apresentado como um material que usa "metodologia comunicativa, textos envolventes, e uma pronúncia forte" e que é "projetado para alunos falarem." (CATÁLOGO, 2016, s.p.). Esse material está sendo, pouco a pouco, substituído por uma nova edição, agora denominada American English File - Second Edition.

A atividade que é objeto de nossa análise faz parte de um capítulo intitulado "Capuccino and fries", que constitui a unidade 2A do livro do aluno, no volume 1 da série (OXENDEN; LATHAN-KOENIG; SELIGSON, 2008, p. 16-17). Segundo o material de orientação do professor (OXENDEN et al., 2008, p. 29), a lição é baseada em entrevistas com estrangeiros que vivem nos Estados Unidos e que foram convidados a falar sobre o modo de vida americano ("the way American people live"). Os mesmos autores prosseguem e afirmam, logo em seguida, que alguns dos comentários expressos não são os estereótipos típicos e

\footnotetext{
2 "Four-skills American English course with a communicative methodology, engaging texts, and a strong pronunciation syllabus - designed to get students speaking."
} 
podem surpreender os alunos. No entanto, observamos que, nessas instruções, o professor não é orientado a trabalhar com estereótipos.

Os exercícios propostos se dividem em cinco categorias (Vocabulary, Reading, Grammar, Pronunciation e Writing \& Speaking) e envolvem ampliação de vocabulário, identificação de palavras conhecidas e desconhecidas em um texto, construção do simple present, pronúncia de sons consonantais e preenchimento de lacunas em que o aluno deve escolher uma entre as duas opções que lhe são previamente fornecidas.

Para discutir imagem e estereótipo a atividade que mais nos chamou a atenção foi a categorizada como Writing \& Speaking, e que reproduzimos a seguir:

FIGURA 1: Atividade proposta

\section{WRITING \& SPEAKING}

a Write your nationality in the title. Then cross out the wrong word(s), e.g., They live in thouse / an apartment. Complete the sentences with your ideas.
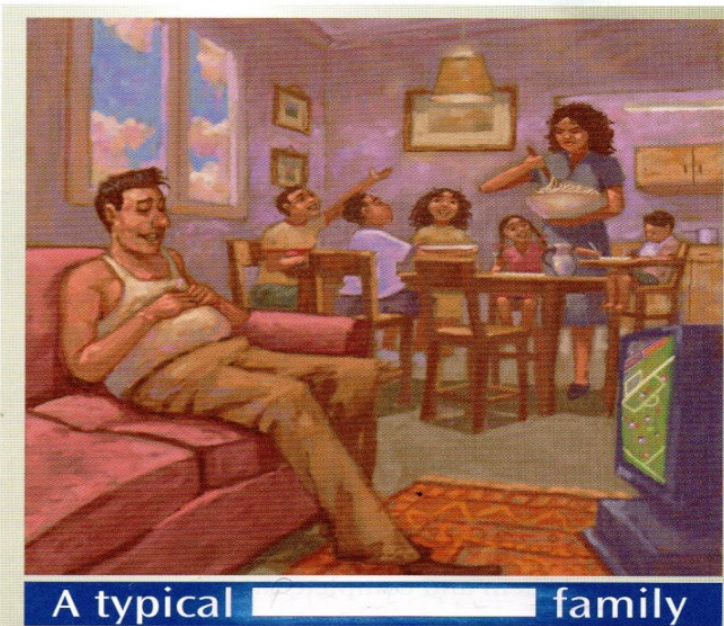

They live in a house / an apartment.

They have / don't have a pet.

They have_child / children.

They go to for their vacation.

The mother works / doesn't work.

She cooks / doesn't cook.

She does / doesn't do housework.

She reads

She watches_on TV.

She drives a

She

The father works / doesn't work.

He cooks / doesn't cook.

He does / doesn't do housework.

He reads

He watches on TV.

He drives a

$\mathrm{He}$

b Read your sentences to a partner. Are they the same or different?

Fonte: OXENDEN, C; LATHAM-KOENIG, C.; SELIGSON (2008, p.17) 
A imagem apresentada retrata uma família que se prepara para uma refeição. Participam da cena sete personagens: um homem, uma mulher e cinco crianças, todas aparentemente de idades muito próximas. Como a atividade na qual está inserida essa imagem tematiza uma "família típica", imagina-se que os adultos sejam os pais das crianças sentadas ao redor da mesa.

Chamam a atenção os papéis assumidos pelos personagens na cena e alguns elementos significativos do cenário apresentado: a mãe é a responsável por, sozinha, servir a refeição aos cinco filhos; enquanto isso, o pai, deslocado do restante do grupo que se organiza em torno da mesa da refeição, assiste a um jogo de futebol sentado no sofá.

A seção Writing \& Speaking é dividida em duas partes, A e B. Observamos que, na parte A, a instrução é composta por três comandos, regidos pelos verbos escreva, risque e complete, sobre os quais discorreremos a seguir. Primeiramente o aluno deverá escrever sua nacionalidade para completar o título ("A typical family"). A forma como ilustração e texto escrito se apresentam na atividade induzem o aluno a entender o título como legenda da imagem. No entanto, observamos que essa imagem serve apenas para ilustrar a atividade, sem que a leitura dela seja necessária para a realização do que é solicitado. Há que se notar, contudo, que ela interfere na interpretação do enunciado, já que o aluno poderá associar a "família típica" de seu país àquela representada na imagem. Assim, o modo como a imagem é utilizada na atividade contrapõe-se ao entendimento de Lemke (2010, p. 456), segundo o qual imagem e texto são indivisíveis na composição de enunciados.

Depois disso, o aluno terá que riscar a(s) "palavra(s) errada(s)" ("wrong word[s]"). São oferecidas duas possibilidades de resposta; o próprio uso do termo "wrong" no enunciado da atividade pressupõe o julgamento de que uma dessas opções esteja errada e a outra certa. Vale lembrar que, como nenhuma das opções dadas apresenta erros gramaticais, entendemos que a noção de "erro" com que trabalham os autores da atividade tem um forte viés cultural. O que seria "certo" ou "errado" para uma "típica" família em um dado país?

Por fim, os autores pedem ainda que o aluno complete as frases com suas ideias. Chama-nos a atenção que, embora eles solicitem que os alunos se manifestem, o espaço reservado para que o façam é destinado apenas ao uso de uma palavra, completando uma ideia pré-concebida, dada pelos próprios autores.

Assim, o aluno é silenciado e levado a repetir o discurso que lhe é imposto, dificultando a relação dialógica que deveria ter com o texto. Observamos também que essa atividade é parte da seção Writing \& Speaking, onde se pressupõe que o aluno deva mobilizar 
as habilidades relacionadas à produção escrita e oral da língua. Isso nos leva a questionar: qual é a visão de escrita e fala contemplada pelos autores?

Na parte B da seção, os alunos, em pares, são convidados a compartilhar e comparar suas ideias. Em nossa visão, esse deveria ser o momento para o professor agir como mediador, estimulando a discussão crítica de estereótipos relacionados ao tema "família", bem como a ideologia dos autores que perpassa a elaboração das atividades e a escolha da imagem utilizada. Entendemos que, por tratar-se de um nível inicial, tais discussões deveriam acontecer em $\mathrm{L}^{3}$ para possibilitar a inclusão de todos os alunos, mesmo os que tenham menor domínio do inglês.

Um dos aspectos que poderiam ser problematizados é o fato de que a figura da mulher representada na ilustração, que cozinha e cuida dos filhos, não condiz com a descrição da mulher que lê, assiste TV e dirige, proposta na sequência de frases apresentadas na parte A. Sabemos que em muitas culturas essas imagens não se excluem, no entanto, no material analisado, elas parecem ser entendidas como opostas. Os alunos poderão não querer admitir estarem representados na ilustração estereotipada, tendendo a se aproximarem mais da descrição de mulher sugerida nas frases e que se aproxima daquela pertencente ao mundo WASP (White, Anglo Saxon, Protestant), segundo mito da mímese ou do colonizador proposto por Scheyerl (2012, p. 47). Como já mencionado anteriormente, o material didático pode gerar no aluno a rejeição da própria identidade e o desejo de ser o outro, em geral pertencente ao círculo central.

Outro aspecto ainda a ser colocado em questão refere-se à ideologia dos autores, editores e produtores do material didático que, segundo Rajagopalan (2012, p. 68), ofusca a nossa capacidade de discernimento e percepção do significado real das coisas. Acreditamos ser papel do professor, dentro da visão crítica, estimular o aprofundamento das reflexões que poderão advir do material proposto. Para tanto, professores e alunos devem estar atentos para implícitos e pressupostos presentes na linguagem de textos verbais e não verbais, propiciando a visão dialógica da linguagem, conforme Bakhtin (2003). Nesse sentido:

[...] baseados nos pressupostos teóricos de Bakhtin, Vygotsky e Freire, entendemos a linguagem não como um sistema fechado, [...] mas como um movimento dialógico, em que a compreensão do processo de interlocução acontecerá como resultado da interpretação e da negociação entre sujeitos sociais. A prática dialógica não é neutra, passiva e linear, mas interessada, política e ideologizada (LEIRO, 2008, p. 159).

\footnotetext{
${ }^{3}$ Neste estudo, referimo-nos a L1 como a língua falada no país em que o material está sendo utilizado.
} 
Entendemos que durante o processo de ensino-aprendizagem de uma língua adicional, seja ela qual for, em contexto escolar, os alunos devem posicionar-se como sujeitos sociais críticos, conscientes, engajados, participantes do universo dialógico da linguagem. Neste sentido, cabe ao professor priorizar a reflexão e a discussão em sala de aula a fim de propiciar uma nova visão sobre o material "adotado". Não restam dúvidas de que o uso do material didático, em especial o LD, facilita o dia a dia do professor, sobrecarregado e subordinado a políticas linguísticas que muitas vezes lhe são impostas. No entanto, o uso crítico que pode ser feito do material é a contribuição que nos propomos a fazer por meio deste estudo.

\section{CONSIDERAÇÕES FINAIS}

Ao realizarmos a análise qualitativa do conteúdo da atividade descrita, o que constatamos por meio de nossas reflexões é que, apesar de pregar uma abordagem comunicativa, que pressupõe uso contextualizado da língua, o que se nota, ao contrário, é uma visão estruturalista de produção escrita em que o aluno apenas é levado a preencher lacunas, sem poder de fato exercer a autoria. Além disso, o manual do professor não sugere reflexão sobre estereótipos ou aspectos culturais que certamente a atividade poderia ensejar. Quanto à produção oral, parece-nos que o aluno de nível inicial é levado apenas a ler em voz alta a sua produção escrita. Ou seja: a fala é mera reprodução da "moldura" encontrada no texto.

Como contribuição deste estudo, sugerimos que poderiam ser trazidos para a discussão em sala de aula outros materiais que externassem modelos diversos e variados de famílias, independentemente de nacionalidades, o que poderia também ser objeto de reflexão. Com visões múltiplas de família, seriam ampliadas também as discussões a respeito das possíveis funções assumidas por homens e mulheres em diferentes comunidades, perspectiva que estaria mais próxima da transculturalidade característica da chamada "modernidade recente", que compreende

[...] uma série de mudanças avassaladoras de natureza econômica, política, tecnológica, cultural e social, em um mundo de complexidade, inseguranças, ambiguidades, instabilidades e, em última análise, de vertigens contínuas sobre crenças, modos de vidas legítimos, conhecimentos válidos, etc (MOITA LOPES, 2013, p. 18).

Tendo em vista esse novo cenário para o ensino de uma língua adicional, concordamos com Leiro (2008) quando afirma que: 
Como professores de línguas, ao entendermos a linguagem não como um sistema fechado, a partir da categoria de decodificação de sentidos, mas como movimento dialógico em que a compreensão da interlocução acontecerá como resultado da interpretação e da negociação entre sujeitos sociais, cabe-nos perseguir uma prática que permita o desvelamento das realidades opressoras, que mantêm os homens imersos na passividade e no acriticismo (LEIRO, 2008, p. 172).

Corroborando o entendimento da autora, acreditamos que somente um olhar crítico poderá transgredir sentidos impostos e estabelecer novos sentidos, negociados e socialmente construídos, contextualizados, que respeitem a diversidade e os múltiplos saberes que fazem da sala de aula terreno fértil para mudanças.

\section{REFERÊNCIAS}

BAKHTIN, M. Os gêneros do discurso. Estética da criação verbal. São Paulo: Martins Fontes, 2003. p. 277-326

BENESCH, S. Critical Praxis as materials development: responding to military recruitment on a U.S. campus. In: HARWOOD, Nigel (Ed.). English Language Teaching Materials:

Theory and Practice. Chapter 5: New York: Cambridge University Press, 2010. p. 109-128.

BROWN, J. D. Curriculum Development. In: ALSAGOFF, L.; McKAY, S. L.; HU, G; RENANDYA, W. A. (Eds.). Principles and Practices for teaching English as an international language. London: Routledge, 2012. p. 147-167.

CATÁLOGO online Oxford University Press, 2016. Disponível em: < https://elt.oup.com/catalogue/items/global/adult_courses/american_english_file/?cc=br\&selLa nguage $=\mathrm{pt}>$

Acesso em: 06 set. 2016

DUDLEY-EVANS, T.; ST JOHN, M. J. Developments in English for Specific Purposes: a multidisciplinar approach. Cambridge: Cambridge University Press, 1998. 301 p.

HARWOOD, N. Issues in material development and design. In: HARWOOD, Nigel (Ed.). English Language Teaching Materials: Theory and Practice. Chapter 1: New York: Cambridge University Press, 2010. p. 3-30.

KAWACHI, G. J.; LIMA, A. P. Aspectos culturais e formação cidadã em um livro didático de inglês para crianças. In: ROCHA, Cláudia Hilstorf; MACIEL, Ruberval Franco (Org.).

Língua Estrangeira e Formação Cidadã: Por entre Discursos e Práticas. Campinas, SP: Pontes, 2013. p. 91-110.

KRAMSCH, C. Context and culture in language teaching. Oxford: Oxford University Press, 1993. 
LANKSHEAR, C.; KNOBEL, M. Pesquisa Pedagógica: do projeto à implementação. Porto Alegre: Artmed, 2008.

LEIRO, E. M. V. F. Os parâmetros curriculares nacionais $(\mathrm{PCN})$ de língua estrangeira e a formação de alunos críticos: a lacuna entre a teoria e a prática. In: GUIMARÃES, E. Texto e discurso: confluências. São Paulo: Editora Mackenzie, 2008. p. 151-175.

LEMKE, J. L. Letramento metamidiático: transformando significados e mídias. In: Trabalhos em Linguística Aplicada., Campinas, 49(2): 455-479, Jul./Dez. 2010

MATSUDA, A. Teaching materials in EIL. In: ALSAGOFF, L.; McKAY, S. L.; HU, G; RENANDYA, W. A. (Eds.). Principles and Practices for teaching English as an international language. London: Routledge, 2012. p. 167- 185.

MOITA LOPES, L. P. Fotografias da Linguística Aplicada brasileira na modernidade recente: contextos escolares. In: MOITA LOPES, L. P. (Org.). Linguística Aplicada na Modernidade Recente. São Paulo: Parábola, 2013. p. 15-37.

MONTE MÓR, W. Crítica e letramentos críticos: reflexões preliminares. In: ROCHA, C. H.; MACIEL, R. F. (Org.). Língua Estrangeira e Formação Cidadã: Por entre Discursos e Práticas. Campinas, SP: Pontes, 2013. p. 31-50.

OXENDEN, C; LATHAM-KOENIG, C.; SELIGSON, P. American English File. Student Book. Oxford: Oxford, 2008, v. 1, 2008, 159 p.

OXENDEN, C; LATHAM-KOENIG, C.; SELIGSON, P.; CLANDFIELD, L.; TARGET, F. American English File. Teacher's Book. Vol 1., 2008, 240 p.

RAJAGOPALAN, K. O papel eminentemente político dos materiais didáticos de inglês como língua estrangeira. In: Denise Scheyerl \& Savio Siqueira (Orgs.). Materiais didáticos para o ensino de línguas na contemporaneidade: contestações e proposições. Salvador: EDUFBA, 2012. p. 37-56.

ROCHA, C. H.; MACIEL, R. F. Língua Estrangeira, formação Cidadã e Tecnologia: Ensino e Pesquisa como Participação Democrática. In: ROCHA, C. H.; MACIEL, R. F. Língua

Estrangeira e Formação Cidadã: Por entre Discursos e Práticas, Vol. 33. Campinas, SP: Pontes, 2013. p. 13-29

ROJO, R. Materiais didáticos no ensino de línguas. In: LOPES, L. P. M. (Org.). Linguística Aplicada na modernidade recente: Festschrift para Antonieta Celani. São Paulo: Parábola, 2013. Cap. 8. p.163-195.

SCHEYERL, D. Práticas ideológicas na elaboração de materiais didáticos para a educação linguística. In: Denise Scheyerl \& Savio Siqueira (Orgs.). Materiais didáticos para o ensino de línguas na contemporaneidade: contestações e proposições. Salvador: EDUFBA, 2012. p. 37-56. 


\section{AS AUTORAS}

Ana Lígia Barbosa de Carvalho e Silva é Mestre em Linguística Aplicada pela Universidade Estadual de Campinas (Unicamp), com bolsa CAPES, e doutoranda em Linguística Aplicada na mesma instituição. Especialista em Recursos para o Ensino de Inglês como Língua Estrangeira pela Universidade Presbiteriana Mackenzie, SP. É examinadora e avaliadora da parte oral do Exame de Proficiência em Português para Estrangeiros (CelpeBras). Por mais de 20 anos, tem atuado como professora de inglês como língua estrangeira para adultos, com especial interesse em inglês no contexto da aviação militar. É membro dos seguintes grupos de estudos: i) Avaliação em contextos de línguas: múltiplos usos e olhares (Unicamp); ii) Estudos em Inglês Aeronáutico, GEIA (ICEA - Instituto de Controle do Espaço Aéreo).

E-mail: analigiasilva7@gmail.com

Luciana Amgarten Quitzau é Licenciada em Letras pela Universidade Estadual de Campinas (Unicamp), Mestre em Linguística Aplicada pela mesma universidade e Doutoranda em Linguística Aplicada também pela Universidade Estadual de Campinas (Unicamp), onde estuda a avaliação de habilidades integradas na prova de Redação do Vestibular Unicamp. Foi professora de Língua Portuguesa da rede particular de ensino por 13 anos. Trabalhou na elaboração de materiais didáticos para o ensino de Língua Portuguesa no Ensino Médio. Atualmente é pesquisadora da COMVEST (Comissão Permanente Para os Vestibulares da Unicamp) e membro do grupo de estudos "Avaliação em contextos de línguas: múltiplos usos e olhares" (Unicamp).

E-mail: lu_amgarten@yahoo.com.br 